\title{
Validity of the EASYCare Standard 2010 assessment instrument for self-assessment of health, independence, and well-being of older people living at home in Poland
}

\author{
Sławomir Tobis ${ }^{1}$ (D) Krystyna Jaracz ${ }^{2} \cdot$ Dorota Talarska $^{3} \cdot$ Sylwia Kropińska $^{4}$. \\ Ewa Zasadzka $^{1}$ - Mariola Pawlaczyk ${ }^{1}$ - Katarzyna Wieczorowska-Tobis ${ }^{4}$. \\ Ian Philp ${ }^{5}$ Aleksandra Suwalska ${ }^{6}$
}

Published online: 3 April 2017

(c) The Author(s) 2017. This article is an open access publication

\begin{abstract}
EASYCare Standard 2010 is a brief instrument identifying concerns in health, functional independence, and well-being, from older persons' perspective. It has not previously been validated for self-assessment. Our aim was to determine whether self-assessment (EC1) can give comparable results to an evaluation performed by professionals (EC2), for older people living at home. The study included community-dwelling individuals (aged at least 60 years, $n=100$; 67 females) without dementia (abbreviated mental test score [AMTS] above 6). It comprised two assessments (self and professional), including summarising indexes: Independence score [IS], Risk of breakdown in care [RBC], Risk of falls [RF], performed within a period between 1 and 2 weeks. Additionally, during EC1, reference tests of physical and mental function (Barthel Index: $96.3 \pm 6.5$, Lawton scale: $6.7 \pm 2.0$, geriatric depression scale: $3.0 \pm 2.7$, AMTS: $10.2 \pm 1.0$ )
\end{abstract}

Responsible editor : D.J.H. Deeg.

Sławomir Tobis

stobis@ump.edu.pl

1 Department of Geriatric Medicine and Gerontology, University of Medical Sciences, Poznan, Poland

2 Department of Neurological and Psychiatric Nursing, University of Medical Sciences, Poznan, Poland

3 Department of Preventive Medicine, University of Medical Sciences, Poznan, Poland

4 Laboratory of Geriatrics, Department of Palliative Care, University of Medical Sciences, Poznan, Poland

5 Warwick Business School, University of Warwick, Coventry, UK

6 Laboratory of Neuropsychobiology, Department of Psychiatry, University of Medical Sciences, Poznan, Poland were applied to test for concurrent validity. Cohen's kappa values (self-assessment vs. professional assessment) across all EASYCare domains were high (0.89-0.95). Results of all summarising indexes derived from self-assessment correlated strongly with reference tests. No differences were found in IS and RBC between EC1 and EC2 $(8.6 \pm 12.0$ vs. $9.0 \pm 12.7$ and $1.0 \pm 1.1$ vs. $1.2 \pm 1.4)$. Results of RF were higher in EC2 $(1.0 \pm 1.1$ vs. $1.1 \pm 1.4$; $p=0.005)$, due to a different response to the item "Do you feel safe outside your home?" We conclude that selfassessment with EASYCare Standard in older people without severe functional impairment living at home can deliver valid results, similar to those obtained through professional assessment, thus providing an efficient system for assessment of relatively independent individuals.

Keywords EASYCare - Self-assessment · Older people · Independence $\cdot$ Functional status

\section{Introduction}

The number of older people is increasing rapidly on a global scale, with impact on the needs of services arising from functional limitations. There is growing interest in person-centred care which responds to individual needs. The designation is "person-centred" rather than "patientcentred", as it involves more than just the health care (American Geriatrics Society Expert Panel on PersonCentered Care 2016). This concept of care provides an adequate support for independence which, in turn, both prevents functional decline and improves well-being (van der Bij et al. 2002).

Comprehensive geriatric assessment (CGA) is a multidisciplinary diagnostic process which is believed to be the 
best method to integrate the care for frail older people (Leichsenring 2004), to plan treatments, and to monitor outcomes. As it is a very complex procedure, a simpler method is needed for everyday use in preventive care for older people living in the community. It should cover a variety of aspects of social and health domains in order to screen for individuals who are in need of support and have increased risk of dependence. It should also incorporate established assessment methods where possible (Philp 1997). The questionnaire EASYCare Standard 2010 may constitute such an instrument (Philip et al. 2014).

The EASYCare questionnaire was introduced in 1997 and subsequently translated into many languages, including Polish (Bień et al. 1999), with reliability and validity demonstrated in various countries in all World Health Organisation (WHO) regions (Philip et al. 2014). In 2010, the tool was presented as EASYCare Standard 2010 - an extended version that benefited from research and clinical activities performed to that date, introducing three summarising indexes (Independence score, Risk of breakdown in care, Risk of falls) which briefly characterise the subject's status (Pinar et al. 2015; Jotheeswaran et al. 2016; Brandão et al. 2015).

It incorporates elements of basic activities of daily living (ADL), selected instrumental activities of daily living (IADL, e.g. cooking, shopping, paying the bills, travelling, etc.), items on safety, accommodation and finances from WHO multinational survey (WHO 1983), and specific items on well-being (Olde-Rikkert et al. 2013). It was shown to be an effective instrument when administered by both health care (van Eijken et al. 2008) and social care practitioners (Clarkson et al. 2009). The use of the instrument by general practitioners (GPs) was effective in prediction of negative health outcomes within one year from the assessment (van Kempen et al. 2015). Also its costeffectiveness was shown in the comparison with usual care in frail older people at 6-month follow-up (Melis et al. 2008). The results of our previous study in a group of older subjects at an oncological surgery clinic (Talarska et al. 2016) showed that the use of the questionnaire allowed to identify functional limitations of older people for planning individual support in order to minimise the risk of disability and hospitalisation. Correlation was found between EASYCare results and those obtained with ADL and IADL scales. The study did not, however, include selfassessment.

With an increasing number of individuals in need of care and limited availability of health and social care professionals, there would be value in having an instrument for self-assessment of social and health functioning. In the study of Brandão et al. (2011), selected parts of the EASYCare questionnaire were used for self-assessment. To the best of our knowledge, to date, the whole EASYCare questionnaire has not been validated for self-assessment.

Our research questions are thus: does self-assessment deliver results as valid as the professional one; our hypothesis therewith is that it does (aspects of construct validity; Terwee et al. 2007), and do results of selfassessment correlate with the ones obtained with reference (gold standard) instruments used in geriatric practice (aspects of concurrent validity that belong to criterion validity as presented in the COSMIN framework; Mokkink et al. 2010)? We therefore compared the results of professional assessment and self-assessment by older participants, and self-assessment against reference instruments in order to determine whether self-assessment has validity for use with some populations of older people who are not frail but at the same time not entirely independent (and not in working age, for whom health risk assessment is recommended; Stuck et al. 2015).

\section{Method}

The project was approved by the bioethical committee of Poznan University of Medical Sciences, Poland.

\section{Participants}

Community-dwelling older people $(n=100)$ entered the study. Participants were volunteers recruited in senior's centres in the city of Poznan (the fifth largest city in Poland); all persons asked to participate expressed their willingness and were included (response rate of 100\%). The inclusion criteria were age (at least 60 years) and absence of severe cognitive impairment [defined as abbreviated mental test score (AMTS) below 7 points]. Participants were provided with a detailed explanation of the study, and an informed consent was obtained. Sociodemographic data were not collected prior to the study, as they are part of the EASYCare questionnaire.

Exclusion criteria were acute conditions or worsening of chronic conditions requiring unplanned medical consultations or a hospitalisation during the observation period ( 2 weeks). None of the screened persons were excluded.

\section{Measures}

The study was composed of two assessments, done at the homes of the participants, based on the EASYCare Standard 2010 questionnaire, within a period between 1 and 2 weeks. The first assessment was performed by the participants themselves (self-completion), and the second one was completed by EASYCare-trained medical staff members of geriatric team, who are regularly involved in 
geriatric assessment, including all reference instruments. They were trained in the use of the EASYCare system and were active in its development within its international network. The professionals were blinded for the scores from self-assessment. The results of these two assessments were compared.

During the first assessment, selected tools of CGA were also used to characterise the functional status of each subject. At the beginning, screening of cognitive status with the AMTS was performed. Thereafter, functional status was defined with Barthel Index (Mahoney and Barthel 1965) and Lawton scale (Lawton and Brody 1969); screening for depression with a short form of geriatric depression scale (GDS; Sheikh and Yesavage 1986) was also undertaken.

AMTS is a brief screening tool showing sensitivity and specificity exceeding $80 \%$ for dementia with scores ranging from 0 to 11 and a cut-off of $<7$ points (Jackson et al. 2013). In our study, all subjects had AMTS results over 6 and were included. Barthel Index is a scale for ADL measurement, with lower scores indicating greater dependency. The score value ranges between 0 and 100 points. Lawton scale is an instrument assessing the dependence in IADL, with score values between 0 and 8 points. GDS is a screening tool for self-assessment of the risk of depression. The short version of GDS, composed of 15 questions, was used, delivering results in the range from 0 to 15 points. Subjects with at least 6 points in the GDS scale were classified as having symptoms of depression.

\section{The EASYCare Standard 2010 questionnaire}

The EASYCare questionnaire underwent a complete cultural adaptation in Poland, and its psychometric properties were evaluated (Bień et al. 1999). In the initial part of the questionnaire personal details and medical history were collected. The socio-demographic data included: sex, age, residence area (rural, urban), current marital status (single including separated/divorced and widowed as well as married/cohabiting), formal education (less than primary, primary, vocational, secondary, higher education), living arrangements (alone, with spouse, with extended family), professional status (employed full-time, employed parttime, unemployed, housewife, pensioner, retired, student). Some aspects were formulated as full text questions: "In general how do your family finances work out at the end of the month?" (not enough to make ends meet, just enough to make ends meet, some money left over), "Are you a carer for someone?" (yes/no), "Does someone provide care for you?" (yes/no/other).

The main part of the questionnaire addresses the functioning of an older person in 7 domains by posing simple questions related to their concerns. The first of them, "seeing, hearing and communicating", includes 4 items, e.g. "Can you use the telephone?". The second domain, "looking after yourself", consists of 13 items, e.g. "Can you wash your hands and face?". The third one, "mobility (getting around)", has 8 items, e.g. "Can you get around indoors?". The fourth domain is "safety", including 5 items, e.g. "Is there anyone who would be able to help you in case of illness or emergency?". The fifth, "accommodation and finances", consists of 3 items, e.g. "In general, are you happy with your accommodation?". The sixth domain, called "staying healthy (prevention)", has 7 items, e.g. "Has your blood pressure been checked recently?". The seventh domain, "mental health and well-being", includes 9 items, e.g. "During the last month, have you often been bothered by feeling down, depressed or hopeless?".

Three summarising indexes were calculated according to the EASYCare Standard 2010 algorithms, based on the analysis performed within the domains listed above:

- Independence score-determines the independence of assessed individual in terms of basic and complex activities of daily living; the final score ranges between 0 and 100 points where higher score indicates greater dependence rate,

- Risk of breakdown in care-determines the risk of hospitalisation; final score ranges 0-12 points-higher score defines increased risk of hospitalisation,

- Risk of falls - the final score ranges 0-8 points; the scores of 3 or more were classified as increased risk of falls.

Independence score contains following items: 1 from the 1st domain ("Can you use the telephone?"), 10 from the 2nd domain ("Can you keep up your personal appearance?", "Can you dress yourself?", "Can you use the bath or shower?", "Can you do your housework?", "Can you prepare your own meals?", "Can you feed yourself?", "Can you take your own medicine?", "Do you have accidents with your bladder (incontinence of urine)?", "Do you have accidents with your bowels (incontinence of faeces)?", "Can you use the toilet (or commode)?"), 6 from the 3rd domain ("Can you move yourself from bed to chair, if they are next to each other?", "Can you get around indoors?", "Can you manage stairs?", "Can you walk outside?", "Can you go shopping?", "Do you have any difficulty in getting to public services? (e.g. doctor, pharmacy, dentist, etc.)"), and 1 from the 5th domain ("Are you able to manage your money and financial affairs?").

Risk of breakdown in care consists of following items: 5 from the 2nd domain ("Can you dress yourself?", "Can you use the bath or shower?", "Can you feed yourself?", "Do you have accidents with your bladder (incontinence of urine)?", "Can you use the toilet (or commode)?"), 1 from the 3rd domain ("Have you had any falls in the last 12 months?"), 1 from the 6th domain ("Do you have any 
concerns about your weight?"), and 5 from the 7th domain ("In general, would you say your health is: (excellent, very good, good, fair, poor)?", "Have you had bodily pain in the past month?", "During the last month, have you often been bothered by feeling down, depressed or hopeless?", "During the last month, have you often been bothered by having little interest or pleasure in doing things?", "Do you have any concerns about memory loss or forgetfulness?").

Risk of falls contains following items: 1 from the 1st domain ("Can you see (with glasses, if worn)?"), 4 from the 3rd domain ("Can you move yourself from bed to chair if they are next to each other", "Do you have any problems with your feet?", "Have you had any falls in the last 12 months?", "Can you walk outside"), 2 from the 4th domain ("Do you feel safe inside your home?", "Do you feel safe outside your home?"), and 1 from the 6th domain ("Do you think you drink too much alcohol?").

\section{Statistical analysis}

The statistical analysis was performed with STATISTICA 12.0 software (StatSoft, Poland). Descriptive results are presented as means and SD. Numbers of persons with concerns in the individual domains are presented as numbers which equal percentages $(n=100)$. Normality in the data distribution was examined with the Shapiro-Wilk test.

Agreement between patient's and researcher's scores (the first research question of our study) on the individual items of the EASYCare Standard 2010 questionnaire was checked using unweighted Cohen's kappa statistic. For the seven domains of the questionnaire, weighted Cohen's kappa was used. The kappa statistic is a chance-corrected measure of the inter-rater agreement. Kappa is interpreted as follows: less than 0.40 indicates poor to fair agreement, $0.41-0.60$ indicates moderate agreement, $0.6-0.8$ represents good agreement, and 0.80-1.00 means excellent agreement (Landis and Koch 1977). Differences between patient's and researcher's average score for the EASYCare summarising indexes were calculated with the Wilcoxon signed-rank test.

Correlations between the self-assessments and the results obtained with reference instruments (second research question) were checked with Spearman's rank correlation coefficient. Dichotomous data were compared with the Chi-square test.

$p<0.05$ was considered statistically significant.

\section{Results}

\section{Characteristics of the study sample}

The mean age of the participants was $73.6 \pm 7.0$ years (range: 60-96 years); among them 67 were females (67\%).
About $1 / 5$ th of the participants were living alone. Less than half were single $(43 \%)$, while the remaining were married; no one was cohabiting. Most of them (over 60\%) had a good financial situation (some money left over from month to month), in spite of the fact that a vast majority (over 90\%) were pensioners or retired. All studied parameters, apart from marital status, were comparable in males and females. The marital status differed also in both analysed age cohorts, with more single subjects in the older group $(p<0.001)$. Detailed socio-demographic characteristics are presented in Tables 1 and 2.

Twenty persons reported to take care of someone on a permanent basis. Forty-eight subjects were not independent in IADL and were recipients of informal care.

The participants were relatively independent; no differences in independence were observed between the younger and the older group. In total, 20 subjects had symptoms of depression (GDS result above 5, whereas none had GDS above 10 points).

\section{Comparison of the two assessments}

No significant differences were found in Independence score and in Risk of breakdown in care between selfassessments and the trained professional's assessments $(8.6 \pm 12.0$ vs. $9.0 \pm 12.7$, and $1.0 \pm 1.1$ vs. $1.2 \pm 1.4$, respectively). As far as the Independence score is concerned, the assessments were slightly different in 26 subjects; in 19 of them, the professional's scores were higher. The Risk of breakdown in care was assessed differently in 8 subjects, where the professional's score was lower.

Differences in the Risk of falls between professional assessment and self-assessment were observed in 21 subjects. In 18 of them, the scores of trained professionals were higher slightly but statistically significantly $(1.0 \pm 1.1$ vs. $1.1 \pm 1.4$; $p=0.005$ ), due solely to the different response to the item "Do you feel safe outside your home?". There were only 2 subjects in whom the assessment done by trained professional identified increased risk of falls (3 points) whereas selfassessment did not ( 2 points). In all remaining subjects, the classification of the Risk of falls was the same despite score differences.

The difference between two assessments of Risk of falls increased with age $(r=0.29 ; p=0.004)$ and was higher in those who were single in comparison with married individuals $(1.2 \pm 1.2$ and $0.8 \pm 1.1 ; p=0.031)$. Also, negative correlation was found between the difference and AMTS $(r=-0.38, \quad p<0.001)$ and Barthel Index $(r=-0.45, p<0.001)$, and positive correlation between the difference and GDS $(r=0.20, p=0.043)$. Moreover, the higher the self-assessment score was the more the trained professional's score deviated from it $(r=-0.41$; $p<0.001)$. 
Table 1 Characteristics of the study sample: sociodemographics
Table 2 Characteristics of the study sample: reference instrument results

\begin{tabular}{|c|c|c|c|}
\hline Variable & Total & Group $1(60-74 y)(n ; \%)$ & Group 2 (over 75y) $(n ; \%)$ \\
\hline \multicolumn{4}{|l|}{ Gender } \\
\hline Females & 67 & $39(66.1)$ & $28(68.3)$ \\
\hline Males & 33 & $20(33.9)$ & $13(31.7)$ \\
\hline \multicolumn{4}{|l|}{ Residence area } \\
\hline Rural & 23 & $14(23.7)$ & $9(22.0)$ \\
\hline Urban & 77 & $45(76.3)$ & $32(78.0)$ \\
\hline \multicolumn{4}{|l|}{ Marital status } \\
\hline Single & 43 & $15(25.4)$ & $28(68.3)$ \\
\hline Married & 57 & $44(74.6)$ & $13(31.7)$ \\
\hline \multicolumn{4}{|l|}{ Living arrangements } \\
\hline Alone & 19 & $6(10.2)$ & $13(31.7)$ \\
\hline With spouse & 23 & $17(28.8)$ & $6(14.6)$ \\
\hline With extended family & 58 & $36(61.0)$ & $22(53.7)$ \\
\hline \multicolumn{4}{|l|}{ Education } \\
\hline Primary & 5 & $2(3.4)$ & $3(7.3)$ \\
\hline Vocational & 23 & $16(27.1)$ & $7(17.1)$ \\
\hline Secondary & 41 & $22(37.3)$ & $19(46.3)$ \\
\hline Higher education & 31 & $19(32.2)$ & $12(29.3)$ \\
\hline \multicolumn{4}{|l|}{ Financial situation } \\
\hline Not enough to make ends meet & 6 & $4(6.8)$ & $2(4.9)$ \\
\hline Just enough to make ends meet & 33 & $21(35.6)$ & $12(29.3)$ \\
\hline Some money left over & 61 & $34(57.6)$ & $27(65.9)$ \\
\hline \multicolumn{4}{|l|}{ Employment status } \\
\hline Employed full-time & 2 & $2(3.4)$ & $0(0.0)$ \\
\hline Employed part-time & 3 & $3(5.1)$ & $0(0.0)$ \\
\hline Unemployed & 0 & $0(0.0)$ & $0(0.0)$ \\
\hline Housewife & 2 & $2(3.4)$ & $0(0.0)$ \\
\hline Pensioner & 89 & $48(81.4)$ & $41(100.0)$ \\
\hline Retired & 4 & $4(6.8)$ & $0(0.0)$ \\
\hline
\end{tabular}

\begin{tabular}{llll}
\hline Instrument & Total & Group 1 (60-74y) & Group 2 (over 75y) \\
\hline $\begin{array}{l}\text { AMTS } \\
\text { Mean } \pm \text { SD } \\
\text { (median; range) }\end{array}$ & $10.2 \pm 1.0$ & $10.3 \pm 1.0$ & $10.2 \pm 0.9$ \\
Barthel & $(10.0 ; 7-11)$ & $(11.0 ; 6-11)$ & $(10.0 ; 7-11)$ \\
Mean \pm SD & & & \\
$($ median; range) & $96.3 \pm 6.5$ & $96.8 \pm 6.9$ & $95.6 \pm 5.9$ \\
GDS & $(100.0 ; 60-100)$ & $(100.0 ; 60-100)$ & $(100.0 ; 80-100)$ \\
Mean \pm SD & & & \\
$\quad($ median; range) & $3.0 \pm 2.7$ & $2.9 \pm 3.0$ & $3.1 \pm 2.3$ \\
IADL & $(2.0 ; 0-10)$ & $(2.0 ; 0-9)$ & $(3.0 ; 0-10)$ \\
Mean \pm SD & & & $6.8 \pm 1.7$ \\
$($ median; range) & $(8.0 ; 0-8)$ & $6.7 \pm 2.2$ & $(8.0 ; 3-8)$ \\
\hline
\end{tabular}

Excellent to good agreement between self-assessment and professional assessment was found for all 49 individual items of the scale. The Cohen's kappa values for the seven domains of the EASYCare questionnaire ranged from 0.89 to 0.95 ; the corresponding data are presented in Table 3. 
Comparison between both assessments concerning the number of participants with at least one need reported in the individual EASYCare domains showed almost perfectly uniform results (Table 4). All participants reported concerns in at least one of the analysed domains. They demonstrated most concerns in the 6th domain (staying healthy-prevention) followed by the 7 th domain (mental health and well-being). The lowest number of concerns was reported in the 1st (seeing, hearing, and communicating), 4th (safety), and 5th (accommodation and finances) domains.

\section{Self-assessment}

The scores of all three summarising indexes were comparable in males and females and were higher in the older age cohort (60-74 vs. 75+): Independence score (6.1 \pm 11.8 vs. $12.1 \pm 11.5, p<0.001)$, Risk of breakdown in care $(2.3 \pm 2.3$ vs. $3.2 \pm 2.0, p=0.007)$, and Risk of falls $(0.7 \pm 1.1$ vs. $1.3 \pm 1.1, p=0.003)$. They were also higher in those who were single in comparison with married individuals: Independence score (11.3 \pm 12.2 vs. $6.5 \pm 11.5, \quad p=0.016)$, Risk of breakdown in care (3.1 \pm 2.4 vs. $2.4 \pm 2.1, p=0.083)$, and Risk of falls $(1.2 \pm 1.2$ vs. $0.8 \pm 1.1, p=0.031)$. A total of 14 persons' scores indicated increased risk of falls.

All three summarising indexes correlated with the functional status of participants (Table 5). The strongest correlation was observed between the indexes and GDS, the weakest with IADL.

\section{Discussion}

In the past 20 years, the EASYCare system has been developed and spread all over the world. It is a brief standardised method for assessing the functioning of older people based on their concerns. Although there are relatively few studies on the implementation of EASYCarebased interventions in the literature, its ease of use has been

Table 3 Weighted Cohen's kappa values for the two assessments (self-assessment vs. trained professional assessment) in all domains of the questionnaire

\begin{tabular}{lll}
\hline & EASYCare domain & Kappa value \\
\hline 1 & Seeing, hearing, and communicating & 0.91 \\
2 & Looking after yourself & 0.95 \\
3 & Mobility (getting around) & 0.95 \\
4 & Safety & 0.95 \\
5 & Accommodation and finances & 0.89 \\
6 & Staying healthy (prevention) & 0.95 \\
7 & Mental health and well-being & 0.92 \\
\hline
\end{tabular}

widely demonstrated in various settings (Craig et al. 2015). Ritters et al. (2012) presented the data from the EASYCare instrument's use for self-assessment and found that over $80 \%$ of participants reported it as very easy or easy to complete. Complementing these findings, the results of our study point to its usefulness in self-assessment which is a key issue of the personalisation agenda (Abendstern et al. 2014). Notably, the applications of the EASYCare system in self-assessment and in the assessment done by trained professionals have not to our knowledge been compared before.

In our study, the self-assessment scores obtained in the three summarising indexes (Independence score, Risk of breakdown in care, and Risk of falls) were consistent with the scores obtained using other tools (AMTS, Barthel Index, Lawton scale, GDS), which provides evidence of concurrent validity for self-assessment in the context of functional disability of older people. In our previous study, similar evidence of concurrent validity was found for the trained professional's perspective in an assessment performed with the EASYCare Standard 2010 questionnaire (Talarska et al. 2016). The strongest correlation of the summarising indexes was observed with the results of GDS screening. This is not surprising as depression is a risk factor of dependence and many other conditions which are common in geriatric care, e.g. malnutrition (KrzyminskaSiemaszko et al. 2016). The weakest correlation was calculated against IADL and Barthel Index which may be partially due to ceiling effects, as the participants had high scores in both scales (Terwee et al. 2007).

We observed excellent agreement between the selfassessment and the assessment performed by trained professionals, and showed the possibility of use of the selfassessment in everyday practice. Our initial hypothesis about construct validity is herewith confirmed. There was a small but statistically significant difference between professional assessment and self-assessment in the Risk of falls scores resulting from different response to the question "Do you feel safe outside your home?" It is noteworthy that only in 2 subjects the assessment done by trained professional identified increased risk of falls whereas selfassessment did not.

Ostbye et al. (1997) demonstrated that differences between the researcher's and patient's perspectives rise with rising stage of dementia. In our opinion, in the absence of dementia, older individuals can reasonably be expected to complete the EASYCare Standard 2010 questionnaire by themselves or with the help of informal caregivers. They should, however, be informed when to contact a professional caregiver, based on the results of the self-assessment.

As far as the limitations of our study are concerned, it must be stressed that the generalisability of the findings should be restricted to older people with good to moderate 
Table 4 Participants with at least one concern reported within the EASYCare domains

$$
\text { EASYCare domain }
$$

Self-

assessment

\begin{tabular}{llll}
\hline 1 & Seeing, hearing, and communicating & 40 & 38 \\
2 & Looking after yourself & 69 & 69 \\
3 & Mobility (getting around) & 48 & 48 \\
4 & Safety & 39 & 39 \\
5 & Accommodation and finances & 42 & 41 \\
6 & Staying healthy (prevention) & 99 & 99 \\
7 & Mental health and well-being & 89 & 90 \\
\hline
\end{tabular}

Table 5 Correlations between the results of self-assessment with EASYCare Standard 2010 questionnaire and functional status

\begin{tabular}{lllllll}
\hline & $\begin{array}{l}\text { Mean } \pm \text { SD } \\
\text { (range) }\end{array}$ & Versus AMTS & Versus Barthel Index & Versus GDS & Versus IADL \\
\hline Independence score & $8.6 \pm 12.0(0-58)$ & $r=-0.30 p=0.002$ & $r=-0.51 p<0.001$ & $r=0.41 p<0.001$ & $r=-0.26 p=0.010$ \\
Risk of breakdown in care & $2.7 \pm 2.2(0-11)$ & $r=-0.26 p=0.008$ & $r=-0.35 p<0.001$ & $r=0.44 p<0.001$ & $r=-0.17 p=0.09$ \\
Risk of falls & $1.0 \pm 1.1(0-5)$ & $r=-0.29 p=0.003$ & $r=-0.36 p<0.001$ & $r=0.50 p<0.001$ & $r=-0.28 p=0.004$ \\
\hline
\end{tabular}

$r$ Spearman's rank correlation coefficients, AMTS abbreviated mental test score, GDS geriatric depression scale, IADL instrumental activities of daily living evaluated with Lawton scale

functional abilities and those without significant cognitive impairment. We did not include those screened for moderate or higher levels of cognitive impairment; the majority of our respondents were independent in ADL and did not report severe limitations or other problems in their functioning. Our sample included individuals who were better educated than observed in a nationwide representative study of PolSenior (Bledowski et al. 2011) which can be viewed as a limitation for the time being; however, it is worth noting that the proportion of the better educated among older people is rising with time.

For subjects with a higher level of disability, separate studies are necessary. Still, at present it can be stated that for mildly dependent individuals the most important difference between professional assessment and self-assessment was in response to the item "Do you feel safe outside your home?", subsequently leading to differences for the whole Risk of falls index. This seems to indicate that older persons with minor disabilities gave a different interpretation to specific aspects of their functioning outside their homes than the professionals.

The results of our study are complemented by the findings by Ruikes et al. (2016) who used EASYCare TOS (two-step older persons screening instrument) to select frail patients for a multicomponent integrated primary care programme. They found that this instrument had limited effectiveness for the identification of patients in need of integrated care, possibly because they were too frail to benefit from this approach. Thus, early screening with the EASYCare self-assessment may have a place ahead of professional assessment for those who are either not frail or pre-frail, and may help to identify individuals for whom further professional assessment is indicated (Challis et al. 2008). The additional advantage of self-assessment is that it potentially allows to save resources and to free up professional staff to concentrate on the assessment of more complex cases (CSED 2006).

Open Access This article is distributed under the terms of the Creative Commons Attribution 4.0 International License (http://creative commons.org/licenses/by/4.0/), which permits unrestricted use, distribution, and reproduction in any medium, provided you give appropriate credit to the original author(s) and the source, provide a link to the Creative Commons license, and indicate if changes were made.

\section{References}

Abendstern M, Hughes J, Tucker S, Clarkson P, Challis D (2014) Self-assessment and personalization in occupational therapy services: a managerial perspective on the challenges and opportunities of a service innovation. $\mathrm{Br} \mathrm{J}$ Occup Ther 77:499-506. doi:10.4276/030802214x14122630932395

American Geriatrics Society Expert Panel on Person-Centered Care (2016) Person-centered care: a definition and essential elements. J Am Geriatr Soc 64:15-18. doi:10.1111/jgs.13866

Bień B, Wojszel BZ, Wilmańska J, Polityńska B (1999) EASY-Care questionnaire: assumptions and study methodology. Gerontol P 7:37-41

Bledowski P, Mossakowska M, Chudek J, Grodzicki T, Milewicz A, Szybalska A, Wieczorowska-Tobis K, Wiecek A, Bartoszek A, Dabrowski A, Zdrojewski T (2011) Medical, psychological and socioeconomic aspects of aging in Poland: assumptions and objectives of the PolSenior project. Exp Gerontol 46:1003-1009. doi:10.1016/j.exger.2011.09.006

Brandão MP, Sousa L, Philp I, Cardoso MF (2011) Self-reported dependency among Portuguese older people living in different 
settings: a cross-sectional study. http://www.ifa-fiv.org/wp-con tent/uploads/2013/11/MariaPiedadeBrandao-1330-Aquamarine. pdf. Accessed 4 June 2016

Brandão MP, Sousa L, Philp I, Cardoso MF (2015) Portuguese older people's self-perception of their (in)dependency: a cross-sectional study. J Aging Innov 4:3-17

Care Services Efficiency Delivery (CSED) (2006) London, Department of Health. http://webarchive.nationalarchives.gov.uk/+/ www.csed.dh.gov.uk/_library/Resources/CSED/DiscussionDoc/ HRADiscDoc_Latest_NEW_FORMAT.pdf. Accessed 5 July 2016

Challis D et al. (2008) Enhancing the efficiency and effectiveness of assessment in community care volume IV self assessment pilot projects: concluding observations discussion paper M180. http:// www.pssru.ac.uk/pdf/MCpdfs/ACCrs.pdf. Accessed 5 July 2016

Clarkson P, Abendstern M, Sutcliffe C, Hughes J, Challis D (2009) Reliability of needs assessments in the community care of older people: impact of the single assessment process in England. J Public Health (Oxf) 31:521-529. doi:10.1093/pubmed/fdp035

Craig C, Chadborn N, Sands G, Tuomainen H, Gladman J (2015) Systematic review of EASY-care needs assessment for community-dwelling older people. Age Ageing 44:559-565. doi:10. 1093/ageing/afv050

Jackson TA, Naqvi SH, Sheehan B (2013) Screening for dementia in general hospital inpatients: a systematic review and metaanalysis of available instruments. Age Ageing 42:689-695. doi:10.1093/ageing/aft145

Jotheeswaran AT, Dias A, Philp I, Patel V, Prince M (2016) Calibrating EASY-Care independence scale to improve accuracy. Age Ageing 42:890-893. doi:10.1093/ageing/afw106

Krzyminska-Siemaszko R, Chudek J, Suwalska A, Lewandowicz M, Mossakowska M, Kroll-Balcerzak R, Wizner B, Tobis S, Mehr K, Wieczorowska-Tobis K (2016) Health status correlates of malnutrition in the polish elderly population-results of the PolSenior Study. Eur Rev Med Pharmacol Sci 20:4565-4573

Landis JR, Koch GG (1977) The measurement of observer agreement for categorical data. Biometrics 33(1):159-174. doi:10.2307/ 2529310

Lawton MP, Brody EM (1969) Assessment of older people: selfmaintaining and instrumental activities of daily living. Gerontologist 9:179-186. doi:10.1093/geront/9.3_Part_1.179

Leichsenring K (2004) Developing integrated health and social care services for older persons in Europe. Int J Integr Care 4:1-15. doi:10.5334/ijic. 107

Mahoney FI, Barthel DW (1965) Functional evaluation: the Barthel Index. Md State Med J 14:61-65

Melis RJ et al (2008) Cost-effectiveness of a multidisciplinary intervention model for community-dwelling frail older people. J Gerontol A Biol Sci Med Sci 63:275-282

Mokkink LB, Terwee CB, Patrick DL, Alonso J, Stratford PW, Knol DL, Bouter LM, de Vet HC (2010) The COSMIN study reached international consensus on taxonomy, terminology, and definitions of measurement properties for health-related patientreported outcomes. J Clin Epidemiol 63:737-745. doi:10.1016/ j.jclinepi.2010.02.006

Olde-Rikkert MG, Long JF, Philp I (2013) Development and evidence base of a new efficient assessment instrument for international use by nurses in community settings with older people. Int J Nurs Stud 50:1180-1183. doi:10.1016/j.ijnurstu.2012.08.007
Ostbye T, Tyas S, McDowell I, Koval J (1997) Reported activities of daily living: agreement between elderly subjects with and without dementia and their caregivers. Age Ageing 26:99-106. doi:10.1093/ageing/26.2.99

Philp I (1997) Can a medical and social assessment be combined? J R Soc Med 90(Suppl 32):11-13

Philip KE, Alizad V, Oates A, Donkin DB, Pitsillides C, Syddall SP, Philp I (2014) Development of EASY-Care, for brief standardized assessment of the health and care needs of older people; with latest information about cross-national acceptability. J Am Med Dir Assoc 15:42-46. doi:10.1016/j.jamda.2013.09.007

Pınar R, Ergün A, Erol S, Kurtuluş Z, Gür K, Sert H, Philp I (2015) The Adaptation of the EASY-Care standard assessment instrument into Turkish and evaluation of psychometric properties among Turkish older people. Nobel Med 11:85-92

Ritters K, Davis H, Philp I, Byrom N, Wiltjer H (2012) Early intervention approaches to ageing in a United Kingdom policy context. http://www.ifa-fiv.org/wp-content/uploads/2013/12/Rit ters-Katrina-Early-Intervention-Approaches-to-Ageing-in-a-Uni ted-Kingdom-Policy-Context.pdf. Accessed 5 July 2016

Ruikes FG, Zuidema SU, Akkermans RP, Assendelft WJ, Schers HJ, Koopmans RT (2016) Multicomponent program to reduce functional decline in frail elderly people: a cluster controlled trial. J Am Board Fam Med 29:209-217. doi:10.3122/jabfm. 2016.02.150214

Sheikh JI, Yesavage JA (1986) Geriatric depression scale (GDS). recent evidence and development of a shorter version. In: Brink TL (ed) Clinical gerontology: A guide to assessment and intervention. The Haworth Press, New York, pp 165-173

Stuck AE, Moser A, Morf U, Wirz U, Wyser J, Gillmann G, Born S, Zwahlen M, Iliffe S, Harari D, Swift C, Beck JC, Egger M (2015) Effect of health risk assessment and counselling on health behaviour and survival in older people: a pragmatic randomised trial. PLoS Med 12:e1001889. doi:10.1371/journal.pmed. 1001889

Talarska D, Pacholska R, Strugala M, Wieczorowska-Tobis K (2016) Functional assessment of the elderly with the use of EASY-Care standard 2010 and comprehensive geriatric assessment. Scand J Caring Sci 30:419-426. doi:10.1111/scs.12241

Terwee CB, Bot SD, de Boer MR, van der Windt DA, Knol DL, Dekker J, Bouter LM, de Vet HC (2007) Quality criteria were proposed for measurement properties of health status questionnaires. J Clin Epidemiol 60:34-42. doi:10.1016/j.jclinepi.2006. 03.012

van der Bij AK, Laurant MG, Wensing M (2002) Effectiveness of physical activity interventions for older adults: a review. Am J Prev Med 22:120-133

van Eijken M, Melis R, Wensing M, Rikkert MO, van Achterberg T (2008) Feasibility of a new community-based geriatric intervention programme: an exploration of experiences of GPs, nurses, geriatricians, patients and caregivers. Disabil Rehabil 30:696-708. doi:10.1080/09638280701400508

van Kempen JA, Schers HJ, Philp I, Olde-Rikkert MG, Melis RJ (2015) Predictive validity of a two-step tool to map frailty in primary care. BMC Med 13:287. doi:10.1186/s12916-015-05199

World Health Organisation (1983) The elderly in eleven countries; a sociomedical survey. World Health Organisation Regional Office for Europe, Copenhagen 